\title{
Categorical discrimination of objects and pictures by pigeons
}

\author{
JUAN D. DELIUS \\ Universität Konstanz, Konstanz, Germany
}

\begin{abstract}
With a three-choice instrumental discrimination procedure, pigeons were taught to distinguish small spherical objects from nonspherical objects. Spherical objects were defined as positive, nonspherical objects as negative. A device allowing an automatic presentation of the stimuli was employed. The subjects actually pecked the objects, and grain rewards were presented directly beside the correct objects. Acquisition was rapid, with the birds reaching a criterion of $80 \%$ correct choices within less than 150 trials. There was evidence that more than 200 objects were remembered individually over 3 months. Pigeons transferred the discrimination of spherical/nonspherical objects to novel objects. The criteria by which the birds judged the sphericity of objects seemed to be similar to those applied by humans. They could apply the categorization in a relational manner and generalize it to apply to photographs and drawings of objects. The categorization competence was retained for at least 3 months.
\end{abstract}

Conceptions of the cognitive capacities of nonhuman vertebrates have developed considerably over the last few decades. Even birds, including pigeons, have been shown capable of remarkable feats of perception, memory, and processing. However, many of the cognitive competencies revealed through laboratory research still fall short of what the natural environment demands. Most of the more spectacular cognitive capacities of pigeons have surfaced only after systematic and prolonged training. Up to thousands of training trials may be necessary before it is possible to demonstrate, for example, perceptual invariance or use of logical concepts in this species. If such extensive training is necessary to bring about these capabilities, it appears doubtful whether pigeons can ever make use of them in the wild, where such protracted conditions are very unlikely. Behaviorists tend to ignore the extreme harshness of life in the natural environment. The mean life expectancy of a pigeon in nature is so short-an average of about 6 months after hatching (Murton, Thearle, \& Thompson, 1972) -that it cannot conceivably afford a long apprenticeship for even the most ecologically valuable cognitive skills. Of course, it is often the case that the extensive training needed in the laboratory serves less to teach subjects the actual target skill than to instruct them

This work was supported by the Deutsche Forschungsgemeinschaft. I thank H. Heinig and W. Longerich for excellent mechanical workmanship, F. Bohle for the development of the electronics, S. Kesch for animal care, G. Keim for photography, L. Zimmermann for artwork, and $A$. Lohmann and $A$. Niemuth for essential assistance with the preparation of the manuscript. I am grateful to J. Emmerton, S. E. G. Lea, and $M$. Rilling for reading a draft and making useful suggestions. S. E. G. Lea also devised and tabulated a special statistical test. The work was partly carried out while the author was still at the Psychologisches Institut, Ruhr-Universität Bochum. Correspondence should be addressed to Juan D. Delius, Allgemeine Psychologie, FG Psychologie, Universität Konstanz, D 7750 Konstanz, Germany. to use it in the particular, contrived context that the experimenter devises. But if that is so, it in turn casts doubts on the efficiency of the instruction procedures currently used in animal cognition research.

In recent years, we have made an effort to devise paradigms that might abbreviate the training required for experiments on the cognitive capacities of pigeons. Ethological considerations have been a guide in this enterprise. The restricted information processing capacities of pigeons must, according to evolutionary theory, be primarily adapted to coping with the learning tasks that are required in nature. Experimental conditioning procedures designed as far as possible to mimic realistic ecological situations can thus be expected to yield optimal learning performance (Delius, 1983; Fersen \& Delius, 1989; Timberlake, 1984; Wright, Cook, Rivera, Sands, \& Delius, 1988).

Two-dimensional visual stimuli have often been employed for research on the perceptual and cognitive abilities of pigeons. From an ecological point of view, these kinds of stimuli are not likely to fit the natural predispositions of pigeons, because significant two-dimensional patterns are not of frequent occurrence outdoors and furthermore are not likely to be particularly important to freeranging pigeons. Nature happens to be three-dimensional. Pigeons can undeniably perceive two-dimensional shapes, but three-dimensional objects may receive more attention and thus be memorized more quickly (see Cowey, 1968; Kay \& Oldfield-Box, 1965; Rothblat \& Hayes, 1987). Some older, rather informal evidence suggests that pigeons may indeed learn to discriminate real objects rapidly (Cumming, 1966; Verhave, 1966).

The present study examines the categorical discrimination of three-dimensional "junk" objects into a spherical and a nonspherical class. Pigeons have already been repeatedly shown capable of categorizing two-dimensional stimuli into a variety of classes, but the understanding of 
the processes involved is still limited. Because of the considerable experimental effort needed, the gap between empirical knowledge and theoretical conceptions is still large (Anderson, Silverstein, Ritz, \& Jones, 1977; Estes, 1986; Fersen \& Lea, 1990; Hermstein, 1990; Lea, 1984; Schank, Collins, \& Hunter, 1986). An experimental paradigm more efficient than those hitherto used could help to close that gap. A procedure was designed that permitted an automated presentation of many small solid objects on a horizontal surface. The pigeons grasped these objects and received reward immediately next to them.

Several issues relating to the categorization competence were investigated with this technique. The acquisition under two different training regimes was compared. The question was whether the number of exemplars would influence the acquisition of the categorization (cf. Lombardi, Fachinelli, \& Delius, 1984). The effect of varying stimulus constellations was examined because there was concern that discrimination may be determined by configurational aspects (cf. Carter \& Werner, 1978; Fersen \& Emmerton, 1989). The transfer of discrimination to novel stimuli was investigated. Such tests are of course necessary to differentiate true open-ended categorization from categorization by rote as defined by Herrnstein (1990). The process by which novel objects acquired the properties of familiar objects was examined. This illuminated how cumulating commerce with specific stimuli leads from an open-ended to a rote categorization. Retention of performance after various experimental pauses was assessed. The expectation was that rote and open-ended categorization may differ in terms of memory persistence (see Hartley \& Homa, 1981). The discrimination transfer from three-dimensional objects to two-dimensional pictures was investigated. It has been suggested that pigeons may not be capable of utilizing depth cues inherent in twodimensional representations (Cerella, 1986) for categorical discrimination. An attempt was made to determine the criteria by which the birds distinguish the spheres from the nonspheres and whether such criteria are applied in a relational manner. This represented an effort to partly specify the representational bases of the open-ended categorization performance. Apart from providing answers to these particular questions, the study is also meant to demonstrate that the method employed is generally well suited for the investigation of complex stimulus discrimination problems in pigeons.

\section{METHOD}

\section{Subjects}

Eight adult homing pigeons (Columba livia) were randomly assigned to two equal groups (A, B). They were of local origin and were housed in individual cages placed in a force-ventilated animal room that was artificially lit on a 12:12-h light:dark cycle. At the beginning of the experiment, they were deprived to $80 \%$ of normal weight, but as they became experienced in the task, their weight was allowed to rise to $90 \%$.

\section{Apparatus}

The apparatus, illustrated in Figure 1, was a Skinner box equipped with a device that allowed the automatic presentation of small ob-

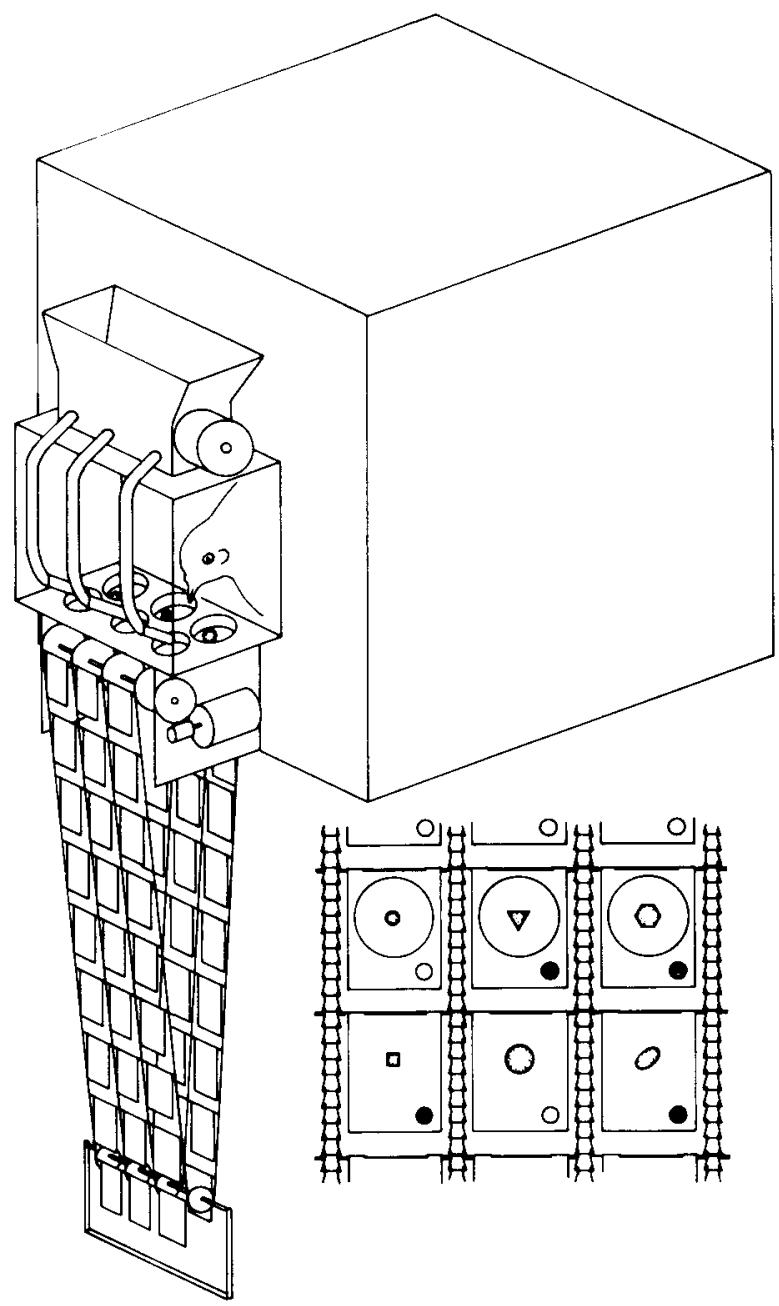

Figure 1. Schematic diagram of apparatus employed for automated real-object discrimination learning by pigeons.

jects. The mechanism, which was based on the principle of conveyor chains, allowed the simultaneous presentation of three objects. Four parallel, cog-driven chain loops had thin traverse bars mounted at regular intervals $(4.5 \mathrm{~cm})$. Three small light-weight metal plates $(3 \times 4 \mathrm{~cm})$, each with an object glued on it, were clipped side by side on each of these bars. There were 24 bars, carrying a total of 72 object plates. As a motor advanced the chains, successive sets of three objects (triplets) were brought into view through as many circular ports (diameter, $2 \mathrm{~cm}$ ) cut into a platform $(15 \times 10 \mathrm{~cm})$. This platform was horizontally attached to the front wall of the animal chamber. The pigeons had access to the working area through a rectangular opening $(15 \times 10 \mathrm{~cm})$ cut into the wall.

When in appropriate position under the ports, each of the object plates rested horizontally on a separate piezo transducer. These transducers were activated when the pigeons pecked the objects. The plates were also equipped with a coding perforation in one of the trailing corners. The perforation could be left open or blocked from underneath with a piece of insulating tape, depending on the kind of object the plate bore. The codes were read by three infrared photoelectric gates. These gates also provided the signal for switching off the motor advancing the chain, so that the stimulus objects would come to rest centered within the viewing ports. To prevent the pigeons from seeing the coding perforations, the objects passed under three hinged flaps that fell back to a vertical position where 
they were held by magnetic catches and closed flush with the object plate surfaces. Data presented later will show that the coding was indeed not a cue that the pigeons could use. The conveyor chains, except for the section bearing the plates currently in view, hung down vertically, kept taut at the bottom by an arrangement of weighted cogs

Reinforcement delivery was arranged so that it was spatially contiguous with the stimulus/response sites. Immediately in front (from the subjects' point of view) of the viewing/response ports were three circular receptacles (diameter, $2 \mathrm{~cm}$; wall, $1 \mathrm{~cm}$ high). Food could be dropped into these through tubes that originated from three separate electromagnetic grain dispensers located on the roof of the working area. When briefly activated, these dispensers deposited between two and six grains of millet into the troughs. The roof also bore three light bulbs ( $2 \mathrm{~W}$ ), two of which illuminated the pigeons' "working" area, the third lighting up for $0.3 \mathrm{sec}$ each time grain was delivered. The working area was enclosed with transparent plastic walls so that the pigeon's choice behavior could be directly observed if desired.

The apparatus was controlled by a microcomputer (Commodore) equipped with a digital input/output interface (DELA). The computer also recorded and stored all relevant experimental data: object codes, response allocation, etc. A printer produced a trial-bytrial protocol as well as a session summary. The computer was programmed with an expanded BASIC suited for on-line control (Xia, Wynne, Münchow-Pohl, \& Delius, 1991).

\section{Stimuli}

Three-dimensional small objects that fitted within a size-limiting $10 \times 12 \times 8 \mathrm{~mm}$ volume served as stimuli. The smallest objects just exceeded an imaginary $1.5 \times 1.5 \times 1.5 \mathrm{~mm}$ cube. There were two types of objects: spherical and nonspherical. The spherical category included objects that ranged from virtually perfect spheres (e.g., ball bearings, marbles), slightly imperfect spheres (pellets, peas), and many-faceted polyhedra (at least duodecadehedra, some slightly irregular) to variously dimpled spheres and diversely textured/surfaced spheres (glossy, glittery, mat painted, pitted, cloth covered, sand surfaced) in all kinds of color variation and made of diverse materials (glass, plastic, ceramic, wood, metal). The category of nonspherical objects was highly heterogeneous and included everything from ovoid-, sausage-, or drop-shaped smooth beads to broken pieces of glass, nuts, bolts, transistors, sequins, buttons, cubes, cylinders, disks, etc. made of the most diverse materials and having varied textures and colors. Many of the objects (both spherical and nonspherical) had small perforations (beads). A sample is shown in Figure 2. The objects were glued to the stimulus-bearing plates with a drop of epoxy glue. The plates were coded according to whether they bore a sphere or not.

\section{Procedure}

The pigeon's task in each trial was to discriminate among three alternative simultaneously presented stimuli. One sphere and two nonspheres were presented in half of the trials; two spheres and one nonsphere were presented in the other half of the trials. The two kinds of trials alternated randomly in an attempt to partially emulate the variable choice situations arising in nature. The right, center, or left position of the sphere and the nonsphere bearing plates occurred according to a quasirandom, counterbalanced sequence. Each session consisted of $\mathbf{4 8}$ trials - two consecutive runs through the 24 stimulus triplets assembled from 36 spheres and 36 nonspheres. As a rule, one session was administered per day except during weekends and under special circumstances that will be specified later.

A trial began when the chain drive stopped and the objects were centered within the viewing ports. The overhead houselight was switched on, and the impact transducers were enabled. A single peck to a sphere, provided that it was forceful enough to activate the corresponding transducer, produced food. The delivery of grain was signaled by a click of the dispenser and a flash of the overhead reward light. The response sensors were disabled. After a feeding period of $2 \mathrm{sec}$, the houselights darkened and the next set of objects was centered under the ports. This stimulus transport or intertrial period lasted approximately $3 \mathrm{sec}$.

Peck to a nonsphere yielded 5-sec time-out: the houselights were switched off, the sensors were disabled, and the objects remained stationary. When the houselights came on again, the pigeon could choose again, and so on until a spherical object was grasped with the consequences just specified. These additional choices were separately recorded and were not included in the percent trials correct scores that will matter later.

\section{Pretraining}

Two A-group pigeons were shaped while the apparatus and program were still being developed. They were first accustomed to the conveyor noise and to the food delivery during several sessions. One bird began to peck the objects spontaneously. The other was

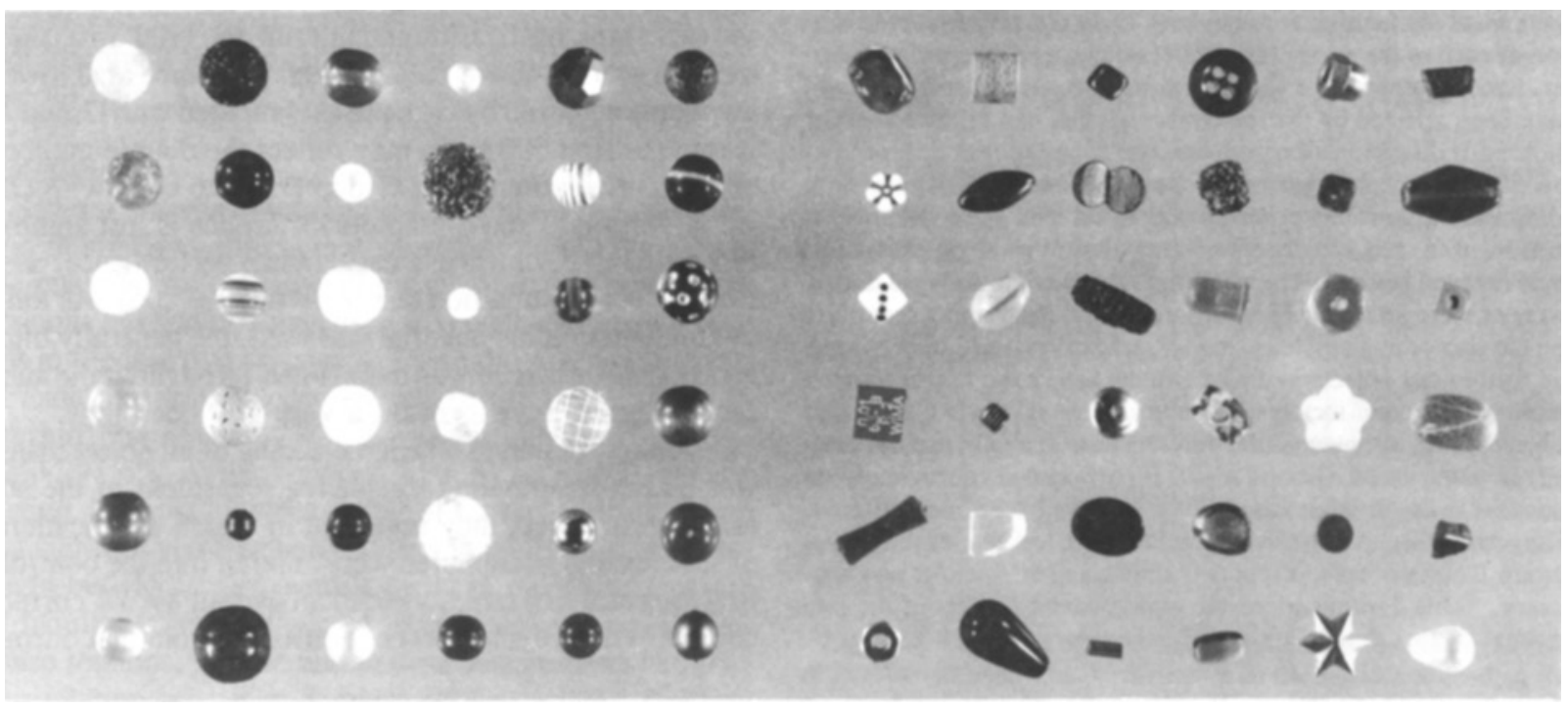

Figure 2. Examples of objects employed. Left, spheres; right, nonspheres. 
enticed to peck them by the placing of a few grains of millet next to the sphere stimuli. The regular training sessions described above followed.

The remaining 6 birds were shaped when the apparatus and program were fully developed and the first birds had already mastered the task. They began with three observation learning sessions in which, from a cage placed next to the working area, they watched 1 of the experienced birds performing. The naive birds could not, however, see the objects that the demonstrator birds pecked. The next sessions were regular training sessions as described above, except that for the first trial, the feeding troughs and the plates bearing spheres were primed with a few grains of millet. This procedure was continued for four sessions.

\section{Acquisition}

The 4 Group A birds were trained to discriminate 18 different spheres and 18 different nonspheres. Two identical replicas of each object yielded the complement of 72 objects needed to fill the stimulus conveyor. The Group B birds learned to discriminate 36 different spheres and 36 different nonspheres. After a few initial sessions in which they took longer, all birds completed their daily sessions in less than $30 \mathrm{~min}$ except very occasionally.

The stimulus objects were randomly rearranged into new triplet combinations every few sessions. After the 14th session, new objects were added to the training collection at irregular intervals. Most but not all of these additional objects were, to begin with, part of transfer tests (see below). When the experiment ended after 80 sessions for Group A birds and after 35 sessions for Group B birds, they routinely discriminated a total of 260 and 184 different objects, respectively, half of them spheres, half of them nonspheres.

\section{Tests}

Several of the tests required only minor changes in procedure. These will be mentioned later along with the results. The tests in which novel stimuli were introduced required more adjustments. They always involved six triplets assembled from objects, or photographs or drawings thereof that had not been employed previously. They were assembled from nine spherical and nine nonspherical stimuli. In analogy with the training arrangements, three triplets consisted of two spheres and one nonsphere each, and the other three triplets consisted of one sphere and two nonspheres each. The position of the test triplets within the sequence of the familiar triplets that completed the session's complement was nearly random. The only constraint was that the first and last three trials of a run always involved familiar stimulus sets. Only the very first presentation of each of the six triplets was evaluated as a measure of transfer. Later presentations were excluded, because such trials could have been affected by the reinforcement that had followed earlier choices. If discrimination performance of any subject dropped below $85 \%$ correct on any particular session, retraining sessions were administered until this criterion was again met. Up to three such sessions were run, mostly on the same day. With some exceptions to be detailed below, all novel objects that were introduced during the tests were immediately incorporated into the training repertoire for the succeeding sessions. It was standard practice to rearrange the former test objects into new triplets before the first retraining session. For rather incidental technical reasons, the two groups of subjects could not undergo the different tests in a fully parallel manner. In some cases, Groups A and B participated concurrently on identical tests; in other cases, their tests and schedules differed. Altogether, Group A was subjected to more test sessions than was Group B. In any case, a separate numbering of sessions was necessary. Table 1 summarizes the experimental history of the two groups; further details are given below.
Table 1

List of Acquisition and Test Sessions for Birds Belonging to Groups $A$ and $B$

\begin{tabular}{lll}
\hline & \multicolumn{2}{c}{ Group } \\
\cline { 2 - 3 } & \multicolumn{1}{c}{ A } & \multicolumn{1}{c}{ B } \\
\hline Acquisition & $1-13$ & $1-10$ \\
Code control & 63 & 32 \\
Shuffling & $20,31,49$ & $22,30,33$ \\
Single spheres & 71 & 24 \\
Retention & $27,41,61$, & 18,35 \\
& $73,58,80$ & \\
Transfer & $14,17,24$, & $11,13,25$, \\
& $29,48,53$, & 35 \\
Definition & $58,75,80$ & \\
Pictures & 50 & $16,21,23$, \\
& $22,34,46$, & 28 \\
Exceptions & $52,56,69$, & \\
Memory & 78 & 35 \\
\hline
\end{tabular}

Note-Remaining sessions were retraining sessions.

\section{Statistics}

Binomial tests were used to assess whether the individual subjects had chosen the different test stimuli according to expectation at levels above chance. A suitable modification of the binomial statistic was necessary when tests involved both trials with an expected chance of $33.3 \%$ and $66.6 \%$ correct choices. For treatment or group comparisons, conventional nonparametric procedures, including the binomial test, were used in the standard manner (Siegel \& Castellan, 1988).

\section{RESULTS}

\section{Acquisition}

Figure 3 shows the mean percent of correct responses plotted as a function of training trials separately for 2 A-group and 4 B-group subjects. Two Group A pigeons were excluded because of their different early training history (see Method). Already by Trial 50 , most subjects showed signs of discriminating, and by Trial 150 , they were all scoring above $80 \%$ correct. The somewhat lower asymptote achieved by Group B as compared with Group A within the first 500 trials may reflect the double number of acquisition stimuli that Group B had to cope with (72 vs. 36 objects). The asymptote difference is just significant when all birds are evaluated (mean performance, Sessions 5-10, permutation test, $n=8, p \approx .05$ ). As long as familiar stimulus material was used, the generally high level of performance was maintained throughout the subsequent sessions, except on a very few occasions.

A control session in which the coding of all object plates was that corresponding to spheres regardless of the actual type of object they bore, but in which the locations of spheres and nonspheres were entered into the controlling program as a table, yielded an overall $89.3 \%$ correct choices. Performance was not different from that during 


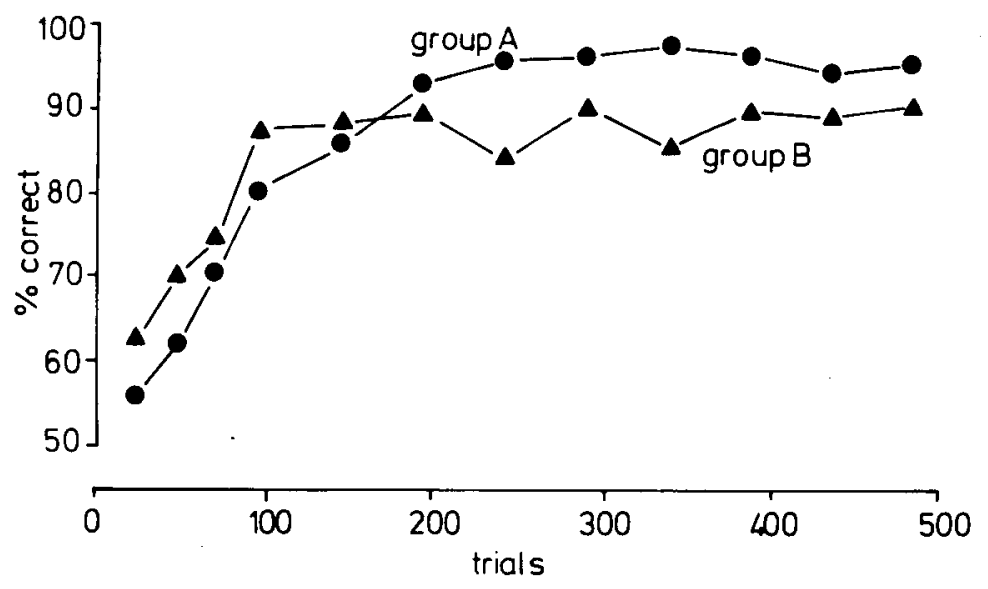

Figure 3. Acquisition of real-object discrimination (spheres vs. nonspheres) by 2 pigeons (Group A) and 4 pigeons (Group B) as a function of trials.

the immediately preceding and following sessions, in which the usual coding was used (Wilcoxon test, $n=8, p \mathrm{~s}>$ $.05)$. This confirms that the coding arrangement was not a cue that the subjects could use.

\section{Generality}

Sessions involving various procedural modifications highlighted the robustness of the subjects' discriminative behavior. The objects in use were frequently all randomly rearranged into new triplets before a given session. This intervention had only a minor, nonsignificant detrimental effect on performance. The mean performance in random selections of three pre- and three postshuffling sessions (see Table 1) was, respectively, $94.3 \%$ and $91.0 \%$ (Wilcoxon test, $n=8, p>.05$ ). A session in which the birds were confronted exclusively with stimulus triplets containing only one sphere and two nonspheres yielded an average $82.7 \%$ correct choices against a chance expectancy of $33.3 \%$ correct, confirming good stimulus control (binomial test for each bird, $p s<.05$; binomial test overall, $n=8, p<.01$ ).

\section{Retention}

Several sessions (see Table 1) involved the presentation of stimulus objects that were thoroughly familiar to the pigeons from at least 10 presentations during earlier sessions but had not been used in recent sessions (at least not in the last five sessions). These did not produce significant performance decrements (mean performance in preshuffling sessions, $92.1 \%$, and in postshuffling sessions, 91.6\%; Wilcoxon test, $n=8, p>.05$ ). Pauses lasting 2 weeks, 3 weeks, and 3 months, during which the subjects were actually experimentally idle, led to a slight but significant overall decay in the discrimination of familiar objects (Figure 4; mean performance in prepause sessions, $92.3 \%$, and in postpause sessions, $86.9 \%$; permutation test, $n=8, p<.05$ ).

\section{Transfer}

Nine category transfer tests were run with Group A and four with Group B (see Table 1). They involved a total of 198 novel objects ( 99 spheres, 99 nonspheres). The new spherical objects differed in size, coloring, patterning, gloss, transparency, inclusions, surface, imperfections, and material from those that the animals had been trained with. The nonspherical objects also differed in shape. The examples in Figure 2 are the 18 spheres and 18 nonspheres used during training (bottom) and the 18 spheres and 18 nonspheres used for the first two tests of Group A (top).

The results of the transfer tests are summarized in Figure 5. The mean transfer performance across all transfer

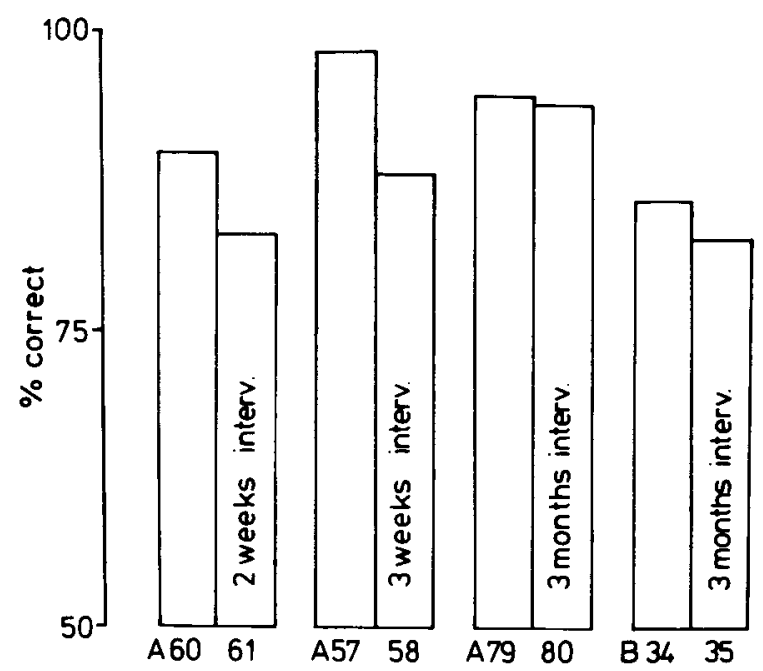

Figure 4. The effect of experimental pauses on the discrimination of familiar objects. The performance in the sessions preceding the pauses are shown for comparison (Groups $\mathbf{A}$ and B). 


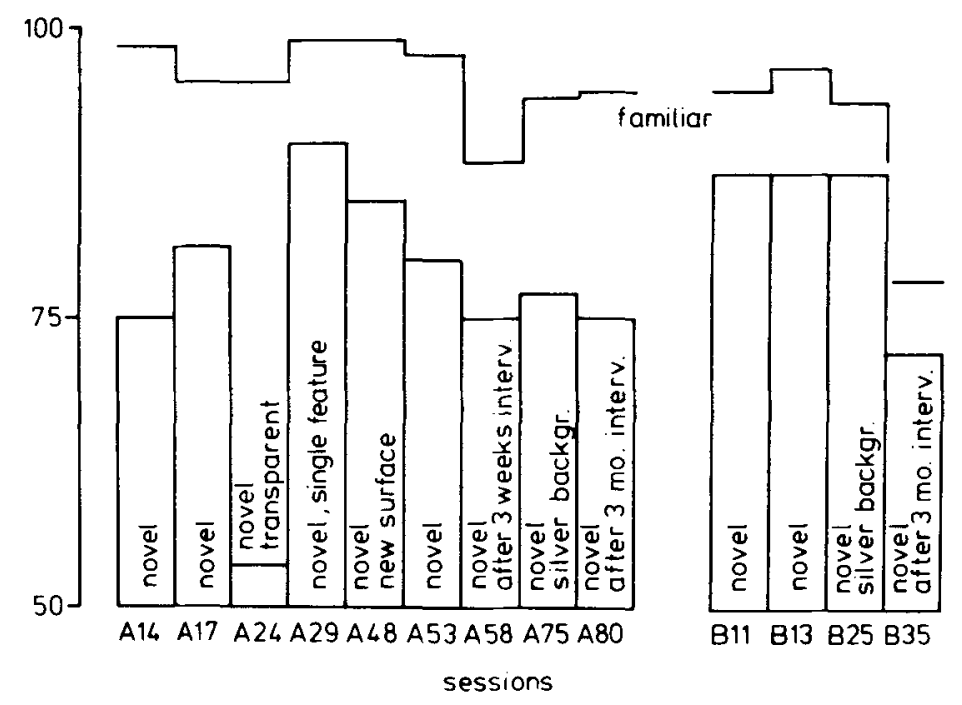

Figure 5. Results of tests in which the transfer of spheres versus nonspheres discrimination to novel objects was examined.

tests, regardless of experimental group, was $79.4 \%$. Overall, each pigeon chose the test spheres at a level above chance (Aa, 42; $\mathrm{Ab}, 43 ; \mathrm{Ac}, 42 ;$ and $\mathrm{Ad}, 40$ correct out of 54 trials; $\mathrm{Be}, 20 ; \mathrm{Bf}, 19 ; \mathrm{Bg}, 20$; and $\mathrm{Bh}, 22$ correct out of 24 trials; binomial tests, $p s<.01$ ). The result is also significant at the population level (binomial test, $n=8, p<.01$ ). The discrimination of familiar objects was generally and markedly better $(\mathbf{9 5 . 3 \%})$ than that of novel objects (Wilcoxon test, $n=8, p<.01$ ).

The only poor transfer result was obtained with transparent glass spheres with "ghosts"-that is, with "floating," opaque, definitely nonspherical inclusions. The latter clearly misled the pigeons. Later, however, when the pigeons were thoroughly familiar with these objects, they were discriminated readily. A test in which the new objects had unusually structured surfaces (sand coated, cloth covered, felt covered) did lead to about average transfer performance. The transfer performance was also affected little when the test objects were mounted for the first time on silvery tin plates rather than the usual brass plates. A test in which the 18 novel stimuli were selected to differ in only one feature (size, color, or surface) from an equal number of familiar training stimuli yielded the best transfer result (see Figure 5).

Group B (many exemplars) was initially at an advantage over Group A (fewer exemplars) regarding transfer to novel objects. Already during the very first tests, Group B yielded a better average performance $(87.4 \%$ vs. $75.0 \%)$. The difference between the groups is significant when the mean performance is compared over the two equivalent transfer tests completed by both groups before Session 20 (A, 77.1\% ; B, 85.5\%; permutation test, $n=8$, $p<.05)$. In later transfer tests, this difference between the groups disappeared and was even reversed. By then, however, because of the unequal adding of objects to the training repertoire (see Method) Group A had dealt with as many familiar objects as had Group B, or with more.

\section{Familiarization}

By combining the data from three sessions with transfer tests and from retraining sessions that followed them in which the originally novel objects continued to be presented though combined into new triplets, it is possible to examine how these objects became gradually familiar through repeated reinforced presentations. In Figure 6, the mean performance on these initially novel stimuli is compared with that on the familiar stimuli that were concurrently used in the same sessions and that had already been presented on 12 or more previous occasions. By their 6th presentation, the novel objects were still not yet quite as well discriminated as the familiar objects (permutation test, $n=8, p \approx .05$ ). The discrimination of the initially novel objects only reached asymptote and became indistinguishable from the discrimination of familiar objects by about the 9th presentation. However, some of the sessions involving Presentations 7-12 also incorporated other, unrelated tests. These seem to have slightly disrupted performance on the stimuli that are relevant here (see Figure 6), but there is no particular reason for assuming that the disruption had a differential effect on the discrimination of novel and familiar stimuli.

\section{Memory}

Long-term retention of transfer competence was demonstrated in test sessions that took place after breaks of 3 weeks and 3 months, during which the animals were experimentally idle (Table 1). Departing from the normal procedure, these sessions began with the six triplets that consisted of novel objects. The ability to categorize 


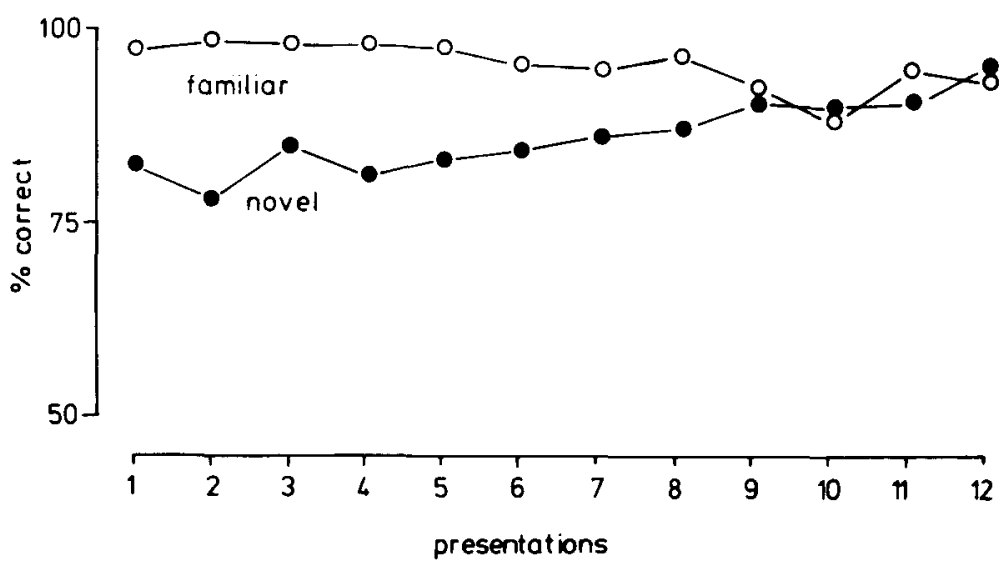

Figure 6. Course of assimilation of novel objects into the familiar set. Note that the familiarization process is only complete after about nine presentations.

unfamiliar stimuli was clearly conserved (see Figure 5). Even after a 3-month pause, each of the 8 birds chose spheres correctly in more trials than chance (significantly so in six cases, binomial tests, $p s<.05$ ), and together they yielded a mean of $72.9 \%$ correct responses (binomial test, $n=8, p<.01$ ). Although the retention seems to have been worse than the mean $84.7 \%$ correct on an approximately comparable transfer test that was not preceded by a retention interval, the difference is not significant (permutation test, $n=8, p>.05$ ). The transfer performance decay, which was $12.3 \%$ over the 3 -month period, compares with a $5.9 \%$ decay on the familiar exemplars over the same period, but the difference is again not significant (permutation test, $n=8, p>.05$ ).

\section{Pictures}

Several tests assessed transfer from real objects to pictures of objects. A first test involved 18 color photographs of training objects familiar to the subjects. Further tests involved similar photographs of novel objects. Analogous tests were conducted with 18 black-and-white photographs of novel objects. A test with 18 black-and-white photographic reproductions of variously shaded pencil or pen drawings of objects closed the series with two-dimensional representations (Figure 7). The overall transfer to blackand-white photographs was best $(79.1 \%)$, that to drawings intermediate $(70.8 \%)$, and that to color photographs worst $(68.7 \%$; Page test, $n=8, p<.01)$. Performance was generally at a lower level than it was in tests in which novel objects were tested (cf. Figures 5 and 8). In particular, the discrimination of monochromatic pictures was significantly worse than that of novel objects in approximately comparable transfer tests $(84.3 \%$; Wilcoxon test, $n=8, p<.01$ ). Nevertheless, 7 birds out of 8 exhibited correct choices above chance over all the picture tests (binomial tests for the 7 birds, $p$ s $<.01$; binomial test overall, $n=8 ; p<.05$ ). The picture stimuli were not incorporated into the training repertoire. Some of them,
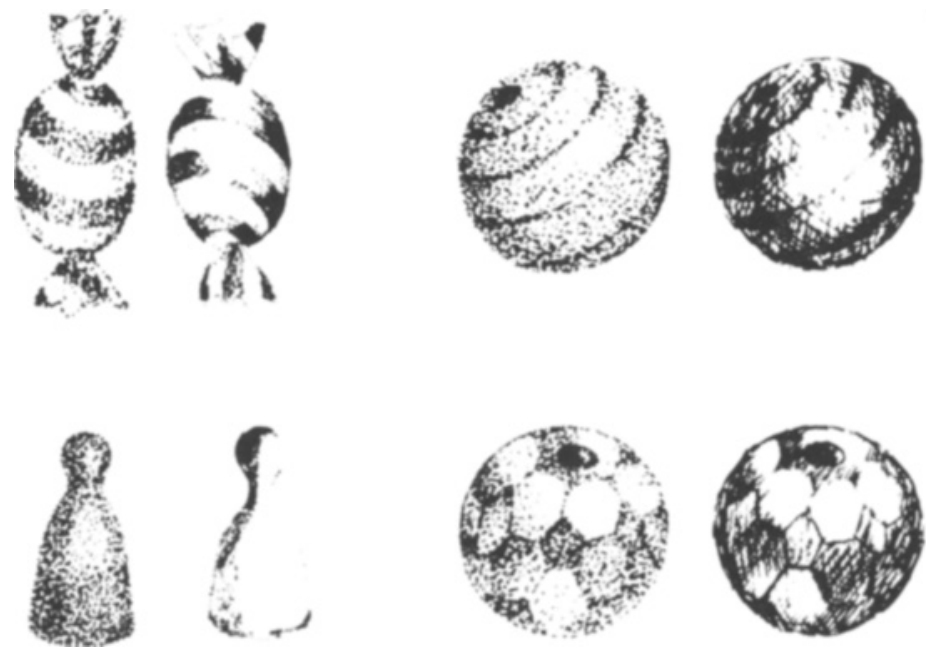

Figure 7. Examples of drawings of objects used in transfer tests. 


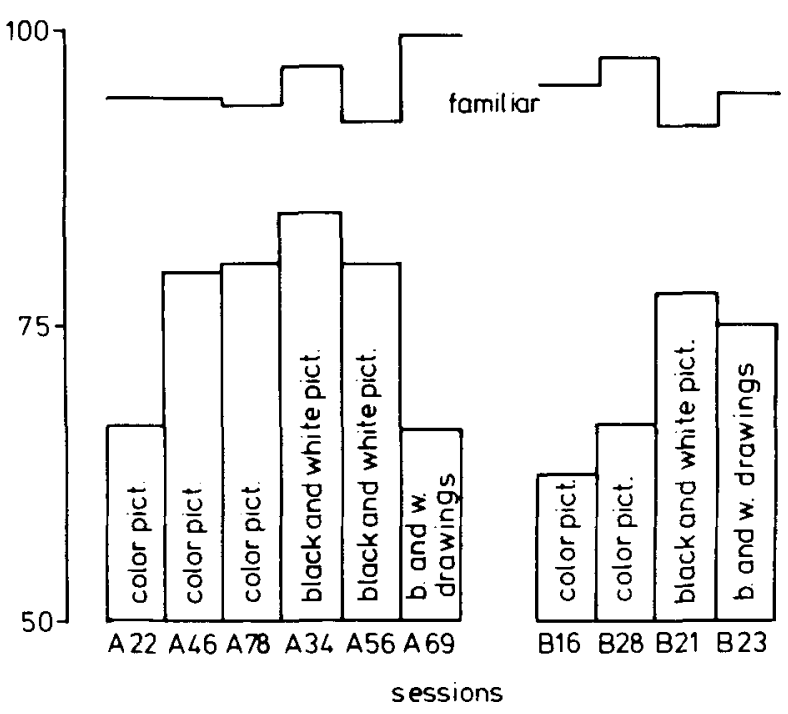

Figure 8. Transfer of the spheres/nonspheres discrimination to photographs and drawings. The columns show the results of tests; the line shows performance with familiar training stimuli (Groups $A$ and $B)$.

however, were later used again on a test in which nine of the stimuli were photographs and the other nine stimuli were objects used in a preceding test. It yielded $75.0 \%$ correct choices. Most errors (five out of six) not surprisingly arose because some nonspherical objects were pecked in preference to photographs of spheres.

\section{Definition}

To explore how the pigeons defined the spherical category, a set of 18 objects was specially selected from among the familiar training stimuli. All belonged to the nonspherical negative set of training stimuli and had been regularly avoided by the pigeons in that context. The stimuli selected varied from somewhat round (drop, ovoid, cigar, lenticular, pill shaped) to definitely nonspherical (disks, elongated cylinders, irregular shapes, etc.). The objects were assembled in sets of 3 as usual. Two human observers ranked the objects within each triplet according to whether they were rather spherical or definitely nonspherical. In $52.0 \%$ of the test trials, the birds chose the object that was defined as the most "spherical" in the set. Each did so significantly above the $33.3 \%$ chance level (binomial test, $p \mathrm{~s}<.05$ ). Furthermore, a preference ranking based on the 4 pigeons' mean choice scores for each object correlated significantly with a sphericity ranking agreed upon by the two persons over all the objects $\left(r_{\mathrm{s}}=.55 ; n=18, p \approx .01\right)$. An object-by-object analysis failed to reveal any features consistently responsible for the few marked disagreements between the two species. In one instance, though, the pigeons are likely to have been influenced by object "dislike" (see below).

\section{Exceptions}

It was noticed in several transfer tests that the pigeons were obviously hesitant to peck certain spheres. Such "dislike" persisted even when the relevant spheres had subsequently become part of the training pool. All birds avoided, for example, a large, aluminized spongy sphere. Out of 24 presentations, it was chosen 3 times, whereas it should have been picked on 16.3 occasions for it to compare with the remaining spheres in use. A similar dislike was apparent with a large brilliant red bead with white dimples. Some dislikes were idiosyncratic: one bird, for example, consistently avoided a particular glossy black rubbery sphere, another a mat turquoise sphere. Some nonspherical objects were repeatedly involved in choice errors. With the exception of the corn mentioned below, they were invariably items that were quasispherical (e.g., ovoid, pill shaped). They caused mistakes particularly when they were part of stimulus triplets that included disliked spheres.

Several of the rejected spheres were above average in size. Size by itself, however, did not determine preferences. In a test in which 10 object triplets included pairs of spheres that were identical except for size (see Table 1), the subjects chose equally often the small $(1.5-3 \mathrm{~mm}$, $35.6 \%)$, medium ( $3-5 \mathrm{~mm}, 31.7 \%)$, and large (5-8 mm, $33.7 \%)$ spheres that were offered.

Another test looked at preferences overriding categorization in a different way. It involved 18 different seeds, all ascertained to be edible for pigeons. Spherically shaped items were chosen in an average of $70.8 \%$ of the trials. Responses to a kernel of corn, however, accounted for four of the seven errors. The 4 birds involved evinced a correspondingly strong preference for corn by eating it first when offered mixed seeds as normal forage in their home cages (cf. Brown, 1969), and they continued to choose it often when it afterwards became part of the training set.

\section{DISCUSSION}

\section{Acquisition}

The acquisition of the sphere/nonsphere discrimination was quite rapid in comparison with that obtained in categorization experiments with more conventional methods (e.g., Herrnstein, 1979). The procedure in which triplets of solid objects were employed as stimuli and operants were presented on the horizontal plane with reward delivered immediately next to the correct stimuli and responses clearly yielded quick learning by pigeons. It must be assumed that it did so because it was closely related to the pigeon's normal foraging situation. There is evidence that methods incorporating some of the same features are also advantageous with mammals, including children (Cowey, 1968; Kay \& Oldfield-Box, 1965; Meyer, Treichler, \& Meyer, 1965; Salmon, Pear, \& Kuhn, 1986; Yaginuma \& Iwai, 1986).

\section{Categorization}

As could be expected from the extensive previous research on the categorization of flat stimuli (Herrnstein, 1990), the pigeons were found capable of generalizing the sphere/nonsphere classification and applying it to novel stimuli. Transfer of discrimination to new objects well 
above chance was obtained on the very first test, soon after the acquisition phase was over. Further transfer tests confirmed this result, with one exception. The exception occurred in a test with transparent spheres that contained nonspherical opaque inclusions. Overall, however, each and all of the 8 birds evinced highly significant categorization behavior. It is notable that although the original discrimination learning among Group A subjects may have been better than that of Group B birds (the former dealt with fewer exemplars than the latter), the transfer performance of Group B was superior in early straight transfer tests than was that of Group $A$. The latter finding is in line with other evidence that the level of transfer of a previously learned complex discrimination to novel test stimuli is directly related to the number of training stimuli used (Lombardi et al., 1984; Wright et al., 1988).

Incidentally, it has not been strictly demonstrated that the pigeons learned the essential sphere/nonsphere distinction within the experiment. It is quite possible that they already possessed it and only learned to apply it in the particular context. It is not uncommon to observe pigeons struggling with "escaping" spherical seeds in the course of normal feeding. Even further, neonate domestic chicks show a definite innate preference for round objects (Fantz, 1957). In the context of a categorical symmetry discrimination study, it was demonstrated that pigeons had a spontaneous preference for asymmetrical shapes before training, indicating the presence of a preexperimental categorization competence (Delius \& Nowak, 1982).

\section{Criteria}

Which cues did the pigeons use to discriminate spheres from nonspheres? A circular perimeter by itself was not the essential criterion, because disks were not confused with spheres (cf. Dawkins, 1969). Roundness alone was not a criterion, since both ellipsoids and ovoids were usually discriminated from spheres. Depth cues due to binocular and scanning parallax (Martinoya, Le Houezec, \& Bloch, 1987; McFadden \& Wild, 1986; see also Aloimonos \& Brown, 1989) were probably important, since pictures of three-dimensional objects were discriminated less accurately than the real objects themselves. Shading and/or texture gradients are likely to have been a factor, since drawings (with less perfect shading/texture cues) yielded performance inferior to that with photographs (with quite naturalistic shading/texture; see Mingolla \& Todd, 1986; Ramachandran, 1988; Witkin, 1981).

Haptic cues may also have played a role. Sensed while the pigeons grasped the object with the beak (cf. Schall \& Delius, 1991), they might have contributed to discrimination, for the pigeons often began to peck the objects while the objects moved into view, before the response detectors were enabled. The tactile stimuli may have acted in two ways, by potentiating visual cues and by being stimuli on their own (Heller, 1985). Haptic cues cannot have been absolutely essential for classification, however, since tests with pictures also yielded categorization.

The spherical/nonspherical object categorization would thus seem to have been based on a number of cues or fea- tures, none of which was by itself essential (polymorphous categorization; see Lea \& Harrison, 1978). Furthermore, each cue may have been "elastic" by virtue of common stimulus (or feature) generalization (Rilling, 1977). In any case, the criteria for sphericity/nonsphericity used by the pigeons seemed to be similar to those applied by humans. When offered only nonspherical objects, the birds also tended to choose those categorized as most "spherical" by humans. It is notable, however, that the same quasispherical objects were routinely classified by the birds as nonspherical when they were paired with true spheres, indicating that, when categorizing, they applied an at least partially relational decision rule (see Pepperberg \& Brezinski, 1991). This finding does not seem compatible with prototype-based categorization mechanisms (e.g., one involving reference to a "distilled" memorized representation of an "ideal" sphere; cf. Watanabe, 1988), since by its very nature, this kind of theory does not provide for relativistic stimulus assessments. For similar reasons, the result cannot be accommodated easily with the conception that open-ended categorization is simply an extension of categorization by rote through simple stimulus generalization (Pearce, 1988).

\section{Memory}

Even after a 3-month interval, the pigeons were clearly capable of accurately discriminating many of the 260 (Group A) or 184 (Group B) training objects. This is in line with other recent evidence of good long-term memory for many visual items in this species (Delius, 1985; Fersen \& Delius, 1989; Vaughan \& Greene, 1984). But novel objects also were classified at levels well above chance after the same experimental pause. This shows that the pigeons had memorized the task both on a by-rote and on an open-ended basis (Herrnstein, 1990). Although it is conceptually convenient to distinguish between these types of information retention, the fact that the rate of performance decay (forgetting) was not significantly different for the two sorts of classification may indicate that the corresponding memory traces are inseparably intertwined (Anderson et al., 1977; Estes, 1986; cf. Hartley \& Homa, 1981). This, however, does not prevent the familiarity/nonfamiliarity dimension from being capable of supporting a stimulus categorization on its own (Fersen \& Delius, 1989; cf. Franchina \& Dyer, 1989).

\section{Pictures}

The pigeons transferred the sphere/nonsphere categorization to pictorial representations of objects. The transfer extended even to photographs of novel objects. This result seems contrary to suggestions by Cerella (1986) but conforms with somewhat preliminary findings of Cabe (1976) and Lumsden (1977) that pigeons recognize the equivalence of two-dimensional representations with the original three-dimensional objects. Other bird species have been previously shown capable of recognizing photographs of conspecifics (Bischof, 1980; Trillmich, 1976).

The finding that the pigeons' discriminative performance was worse with pictures than with objects is con- 
sistent with the finding that chickens attend to solid objects more than to flat shapes when they peck for food immediately after hatching and that when given only twodimensional pictures they respond to those that most accurately reflect the three-dimensional nature of solid objects (Dawkins, 1969; Hershberger, 1970). The fact that the pigeons did worst with color photographs can be ascribed to the fact that their color vision is at least pentachromatic (Emmerton, 1983), whereas color photography is matched to the trichromatic color vision of humans. Color photographs are probably poor, false color representations of real objects for pigeons, a circumstance that tends to be disregarded in the literature.

The equation of pictures and objects, however, is not perfect in humans either, and it may in fact be quite reduced in very young children (Slater, Rose, \& Morrison, 1984) and in adults that have no habitual experience with graphic representations (Deregowski, 1989). Most experiments with primates indicate that they can generally recognize objects represented in pictures (see Herzog \& Hopf, 1986, for a review), but some striking failures have also been reported (Winner \& Ettlinger, 1979). In rhesus monkeys, certain specialized cortical neurons respond preferentially to real faces rather than photographs of faces (Perret et al., 1984). Pigeons nevertheless recognize the equivalence of shape outlines with shape silhouettes, and less well, the equivalence between shapes in reverse contrast (Lombardi \& Delius, 1989). They also detect the correspondence between structured/shaded drawings and silhouettes, though perhaps not between the former and outlines (Cook, Wright, \& Kendrick, 1987).

\section{Conclusions}

It is an inevitable consequence of the bioevolutionary process that behavioral competencies of animals come to match the demands that their normal environment makes. There is no a priori reason to suppose that cognitive capacities are excepted from this. Thus, laboratory situations designed to mimic natural contexts are the most likely to reveal the more complex forms of information processing that a given species is capable of. Herrnstein (1990) has drawn attention to the possibility that negative experimental evidence concerning certain cognitive abilities of pigeons may well be due to the use of suboptimal methods. The procedure successfully employed here to demonstrate that pigeons can categorize objects according to the rather abstract characteristic of sphericity may well be better suited for the purpose than more standard procedures are. Future work will have to show whether it can elicit more intelligent behavior in pigeons than more conventional methods do.

\section{REFERENCES}

Aloimonos, J., \& Brown, C. M. (1989). On the kinetic depth effect. Biological Cybernetics, 60, 445-455.

Anderson, J. A., Silverstein, J. W., Ritz, S. A., \& Jones, R. S. (1977). Distinctive features, categorical perception, and probability learning: Some applications of a neural model. Psychological Review, 84, 413-451.

Bischof, H. J. (1980). Reaktionen von Zebrafinkenmännchen auf zweidimensionale Attrappen: Einflu $\beta$ von Reizqualität und Prägung. Journal für Ornithologie, 121, 288-290.

Brown, R. G. B. (1969). Seed selection of pigeons. Behaviour, 34, 115-131.

CABE, P. A. (1976). Transfer of discrimination from solid objects to pictures by pigeons: A test of theoretical models of pictorial perception. Perception \& Psychophysics, 19, 545-550.

Carter, D. E., \& Werner, J. T. (1978). Complex learning and information processing in pigeons: A critical analysis. Journal of the Experimental Analysis of Behavior, 29, 565-601.

Cerella, J. (1986). Pigeons and perceptions. Pattern Recognition, 19, 431-438.

Cook, R. G., Wright, A. A., Kendrick, D. F. (1987). Visual categorization in pigeons. In M. L. Commons, S. M. Kosslyn, \& R. J. Herrnstein (Eds.), Pattern recognition and concepts in animals, people, and machines (pp. 187-214). Hillsdale, NJ: Erlbaum.

Cowey, A. (1968). Discrimination. In L. Weiskrantz (Ed.), Analysis of behavioral change (pp. 189-238). New York: Harper \& Row.

Cumming, W. W. (1966). A bird's eye glimpse of men and machines. In R. Ulrich, T. Stachnik, \& J. Mabry (Eds.), Control of human behavior (pp. 246-256). Glenview, IL: Scott Foresman.

DAwkINS, R. (1969). The ontogeny of a pecking preference. Zeitschrift fiur Tierpsychologie, 25, 170-186.

De Lius, J. D. (1983). Learning. In M. Abs (Ed.), Physiology and behaviour of the pigeon (pp. 327-353). London: Academic Press.

Deuus, J. D. (1985). Cognitive processes in the pigeon. In G. d'Ydewalle (Ed.), Cognition, information processing, and motivation (pp. 3-18). Amsterdam: Elsevier.

Delius, J. D., \& Nowak, B. (1982). Visual symmetry recognition by pigeons. Psychological Research, 44, 199-212.

DeREgowski, J. B. (1989). Real space and represented space: Cross cultural perspectives. Behavioral \& Brain Sciences, 12, 51-119.

Emmerton, J. (1983). Vision. In M. Abs (Ed.), Physiology and behaviour of the pigeon (pp. 243-266). London: Academic Press.

Estes, W. K. (1986). Array models for category learning. Cognitive Psychology, 18, 500-549.

FANTZ, R. L. (1957). Form preferences in newly hatched chicks. Journal of Comparative \& Physiological Psychology, 50, 422-430.

FERSEN, L. von, Delius, J. D. (1989). Long term retention of visual stimuli by pigeons. Ethology, 82, 141-155.

FERSEN, L. VON, \& EMMERTON, J. (1989). Valorización direccional de estímulos por palomas en una discriminaciåon condicional. Revista Mexicana del Análisis de la Conducta, 13, 273-285.

Fersen, L. von, \& LeA, S. E. G. (1990). Category discrimination with polymorphous features. Journal of the Experimental Analysis of Behavior, 54, 69-84.

Franchina, J. J., \& Dyer, A. B. (1989). Cross-modality transfer effects in conditioning-enhanced neophobia in chicks (Gallus domesticus): Evidence for the separability of novelty from specific stimulus characteristics. Animal Learning \& Behavior, 17, 261-265.

Hartley, J., \& HоMA, D. (1981). Abstraction of stylistic concepts. Journal of Experimental Psychology: Human Learning \& Memory, 7, 33-46.

Heller, M. A. (1985). Tactual perception of embossed Morse code and braille: The alliance of vision and touch. Perception, 14, 563-570.

HeRRNSTEIN, R. J. (1979). Acquisition, generalization, and discrimination reversal of natural concept. Journal of Experimental Psychology: Animal Behavior Processes, 5, 116-129.

HeRRNSTEIN, R. J. (1990). Levels of stimulus control: A functional approach. Cognition, 37, 133-166.

HERshberger, W. (1970). Attached-shadow orientation perceived as depth by chickens reared in an environment illuminated from below. Journal of Comparative \& Physiological Psychology, 73, 403-411.

Herzog, M., \& HopF, S. (1986). Recognition of visual pattern components in squirrel monkeys. European Archives of Psychiatry \& Neurological Science, 236, 10-16.

KAY, H., \& OLDFIELD-BOX, H. (1965). A study of learning-sets in rats 
with an apparatus using 3-dimensional shapes. Animal Behaviour, 13, 19-23.

LEA, S. E. G. (1984). In what sense do pigeons learn concepts? In H. L. Roitblat, T. G. Bever, \& H. S. Terrace (Eds.), Animal cognition (pp. 263-276). Hillsdale, NJ: Erlbaum.

LEA, S. E. G., Harrison, S. N. (1978). Discrimination of polymorphous stimulus sets by pigeons. Quarterly Joumal of Experimental Psychology, 30, 521-537.

Lombardi, C. M., \& Delius J. D. (1989). Pattern recognition invariance in pigeons: Outline, color and contrast. International Journal of Comparative Psychology, 2, 83-102.

Lombardi, C. M., Fachinelu, C. C., \& Delius, J. D. (1984). Oddity of visual patterns conceptualized by pigeons. Animal Learning \& Behavior, 12, 2-6.

LUMSDEN, E. A. (1977). Generalization of an operant response to photographs and drawings/silhouettes of a three-dimensional object at various orientations. Bulletin of the Psychonomic Society, 10, 405-407.

MCFADDEN, S. A., \& WILD, J. M. (1986). Binocular depth perception in the pigeon (Columba livia). Journal of the Experimental Analysis of Behavior, 45, 149-160.

Martinoya, C., Le Houezec, J., \& Bloch, S. (1987). Depth resolution in the pigeon. Journal of Comparative Physiology, 163A, 33-42.

Meyer, D. R., Treichler, F. R., Meyer, P. M. (1965). Discretetrial training techniques and stimulus variables. In A. M. Schrier, H. F. Harlow, \& F. Stollnitz (Eds.), Behavior of nonhuman primates: Modem research trends (Vol. 1, pp. 1-45). New York: Academic Press.

Mingolla, E., \& Todd, J. T. (1986). Perception of solid shape from shading. Biological Cybernetics, 53, 137-151.

Murton, R. K., Thearle, R. J. P., \& Thompson, I. (1972). Ecological studies of the feral pigeon, Columba livia var. Journal of Applied Ecology, 9, 835-874.

PeArCe, J. M. (1988). Stimulus generalization and the acquisition of categories by pigeons. In L. Weiskrantz (Ed.), Thought without language (pp. 133-155). Oxford: Oxford University Press/Clarendon Press.

Pepperberg, I. M., Brezinski, M. V. (1991). Acquisition of a relative class concept by an African grey parrot (Psittacus erithacus): Discrimination based on relative size. Joumal of Comparative Psychology, 105, 286-294.

Perret, D. I., Smith, P. A. J., Potter, D. D., Mistlin, A. J., Head, A. S., Milner, A. D., \& Jeeves, M. A. (1984). Neurons responsive to faces in the temporal cortex: Studies of functional organization, sensitivity to identity and relation to perception. Human Neurobiology, 3, 197-208.

Ramachandran, V. S. (1988). Perceiving shape from shading. Scientific American, 259, 58-65.

RILling, M. (1977). Stimulus control and inhibitory processes. In W. K. Honig \& J. E. R. Staddon (Eds.), Handbook of operant behavior (pp. 432-480). Englewood Cliffs, NJ: Prentice-Hall.
Rothblat, L. A., HAyes, L. L. (1987). Short-term object recognition memory in the rat: Nonmatching with trial-unique junk stimuli. Behavioral Neuroscience, 101, 587-590.

Salmon, D. J., Pear, J. J., KuhN, B. A. (1986). Generalization of object naming after training with picture cards and with objects. Joumal of Applied Behavior Analysis, 19, 53-58.

Schall, U., \&eluus, J. D. (1991). Grasping in the pigeon: Control through sound and vibration feedback mediated by the nucleus basalis. Physiology \& Behavior, 50, 983-988.

Schank, R. C., Coluns, G. C., \& Hunter, L. E. (1986). Transcending inductive category formation in learning. Behavioral \& Brain Sciences, 9, 639-686.

Siegel, S., \& Castellan, N. J. (1988). Nomparametric statistics for the behavioral sciences. New York: McGraw-Hill.

Slater, A., Rose, D., Morrison, V. (1984). Newborn infants' perception of similarities and differences between two- and threedimensional stimuli. British Journal of Developmental Psychology, 2, 287-294.

Trillmich, F. (1976). Learning experiments on individual recognition in budgerigars (Melopsittacus undulatus). Zeitschrift fur Tierpsychologie, 41, 372-395.

Ttmberlake, W. (1984). An ecological approach to learning. Leaming \& Motivation, 15, 321-333.

Vaughan, W., \& Greene, S.L. (1984). Pigeon visual memory capacity. Joumal of Experimental Psychology: Animal Behavior Processes, 10, 256-271.

VERHAVE, T. (1966). The pigeon as a quality-control inspector. In R. Ulrich, T. Stachnik, \& J. Mabry (Eds.), Control of human behavior (pp. 242-246). Glenview, IL: Scott Foresman.

WATANABE, S. (1988). Failure of visual prototype learning in the pigeon. Animal Learning \& Behavior, 16, 147-152.

WinNer, E., \& ETTLINGER, G. (1979). Do chimpanzees recognize photographs as representations of objects? Neuropsychologia, 17, 413-420.

WITKIN, A. P. (1981). Recovering surface shape and orientation from texture. Artificial Intelligence, 17, 17-45.

Wright, A. A., Cook, R. G., Rivera, J. J., Sands, S. F., Deluus, J. D. (1988). Concept learning by pigeons: Matching-to-sample with trial-unique video picture stimuli. Animal Learning \& Behavior, 16, 436-444.

XIA, L., Wynne, C. D. L., Münchow-Pohl, F. von, DeluUs, J. D. (1991). PSYCHOBASIC: A BASIC dialect for the control of psychological experiments with the Commodore-64 and DELA interfacing. Behavior Research Methods, Instruments, \& Computers, 23, 72-76.

YAGINUMA, S., \& IwaI, E. (1986). Effect of small cue-response separation on pattern discrimination in macaques (Macaca fuscata and M. mulatta). Joumal of Comparative Psychology, 100, 137-142.

(Manuscript received October 16, 1989; revision accepted for publication January 2, 1992.) 